\title{
NEUMOESCROTO SECUNDARIO A ENFISEMA SUBCUTÁNEO MASIVO TRAS DRENAJE DE UN NEUMOTÓRAX ESPONTÁNEO
}

A. MATEOS COLINO*, R. GOLPE GÓMEZ*, A. GONZÁLEZ RODRÍGUEZ**, A. SOUSA ESCANDÓN***, C. GONZÁLEZ URIBARRI***, M. SEIRULO SALAS*

Servicio de Medicina Interna/Neumología*. Servicio de Radiología**. Servicio de Urología***. Hospital Comarcal de Monforte de Lemos. Lugo.

Actas Urol Esp. 28 (8): 606-609, 2004

\section{RESUMEN}

NEUMOESCROTO SECUNDARIO A ENFISEMA SUBCUTÁNEO MASIVO TRAS DRENAJE DE UN NEUMOTÓRAX ESPONTÁNEO

Presentamos un caso excepcional de presentación de un neumoescroto y neumopene que apareció tras la colocación de un tubo de tórax para el drenaje de un neumotórax espontáneo recidivado. A pesar de tratarse de una entidad de fácil diagnóstico y tratamiento conservador, puede confundirse con otros cuadros más graves y cuyo tratamiento es mas invasivo.

PALABRAS CLAVE: Neumoescroto. Neumopene. Neumotórax. Drenaje torácico. Complicaciones.

\section{ABSTRACT \\ PNEUMOSCROTUM SECONDARY TO A MASIVE SUBCUTANEOUS EMPHYSEMA AFTER EXPONTANEOUS NEUMOTHORAX DRAINAGE}

We present a case of a pneumoscrotum and pneumopenis which appeared after a trocar drainage placement for treatment of a recidivated expontaneous pneumothorax. In spite of is an entity with easy diagnosis and conservative management, maybe be confused with other more agresive entities which treatment should be invasive.

$\mathrm{E}^{1}$ neumoescroto es una entidad clínica poco frecuente, raramente descrita en la literatura médica. La presencia de gas escrotal se debe, la mayoría de las veces, a procesos infecciosos o a hernias del intestino que han pasado al saco escrotal. Sin embargo, existen muchas otras posibles etiologias para el neumoescroto y es preciso tenerlas en cuenta en el diagnóstico diferencial. No debe confundirse este proceso benigno con otras entidades graves y amenazantes para la vida, que precisan terapias quirúrgicas agresivas.
Presentamos el caso de un varón en el que la manifestación clínica más llamativa de un enfisema subcutáneo masivo, secundario a la colocación de un tubo de drenaje por neumotórax, era un neumoescroto con pneumopenis.

\section{CASO CLÍNICO}

Paciente varón de 70 años, exfumador de 40 paquetes-año, diagnosticado de EPOC en estadio III de la clasificación GOLD, que había precisado múltiples ingresos previos por exacerbación aguda 
de su enfermedad. Presentaba habitualmente Insuficiencia Respiratoria Crónica por lo que seguía terapia habitual con oxígeno domiciliario. Cinco años antes del ingreso actual había presentado un episodio de neumotórax espontáneo que precisó tubo de drenaje. Ingresa por presentar cuadro de disnea brusca y dolor costal derecho. A la exploración presentaba mal estado general, con taquípnea, aumento del trabajo respiratorio con uso de musculatura accesoria, sudoración fría y mala perfusión periférica. Se objetivó abolición del murmullo vesicular en el hemitórax derecho. La radiografía de tórax mostraba un neumotórax masivo derecho. Se colocó un tubo de drenaje torácico conectado a una válvula de Heimlich, consiguiéndose la reexpansión pulmonar, y retirándose el drenaje a las 48 horas. Al séptimo día del ingreso presentó fiebre de $38,5^{\circ}$, incremento de expectoración de coloración verdosa y quebrantamiento del estado general. A la exploración se objetivaron roncus difusos y crepitantes en tercio medio de pulmón izquierdo. En la radiología de tórax se apreció infiltrado alveolo-intersticial en LII. En esputo creció $P$. aeruginosa en cultivo puro. Se inició tratamiento con ceftazidima y gentamicina. El paciente presentó buena evolución, quedando afebril en 36 horas y mejorando clínicamente. Una semana más tarde, presentó nuevamente incremento brusco de disnea. Una nueva radiografía de tórax volvió a evidenciar un neumotórax derecho. Se colocó de nuevo un tubo de drenaje torácico, con mejoría subjetiva del paciente. En la radiografía realizada 24 horas después de la colocación de este tubo se apreció un enfisema subcutáneo en la región axilar derecha, que no se apreciaba en otras localizaciones. Al día siguiente el paciente se quejó de hinchazón muy llamativa de la bolsa escrotal, que había adquirido un tamaño de unos $15 \mathrm{~cm}$ de diámetro, así como del pene, el cual también había aumentado en diámetro (Fig. 1). A la palpación presentaba sensación de crepitante, sin dolor ni signo de oleada. En el resto de la exploración se apreció un llamativo enfisema subcutáneo en cuello, llegando hasta la zona auricular, en parte anterior de tórax, parte interna de ambos brazos, llegando incluso hasta parte anterior de ambas muñecas. Había asimismo afectación de pared abdominal,

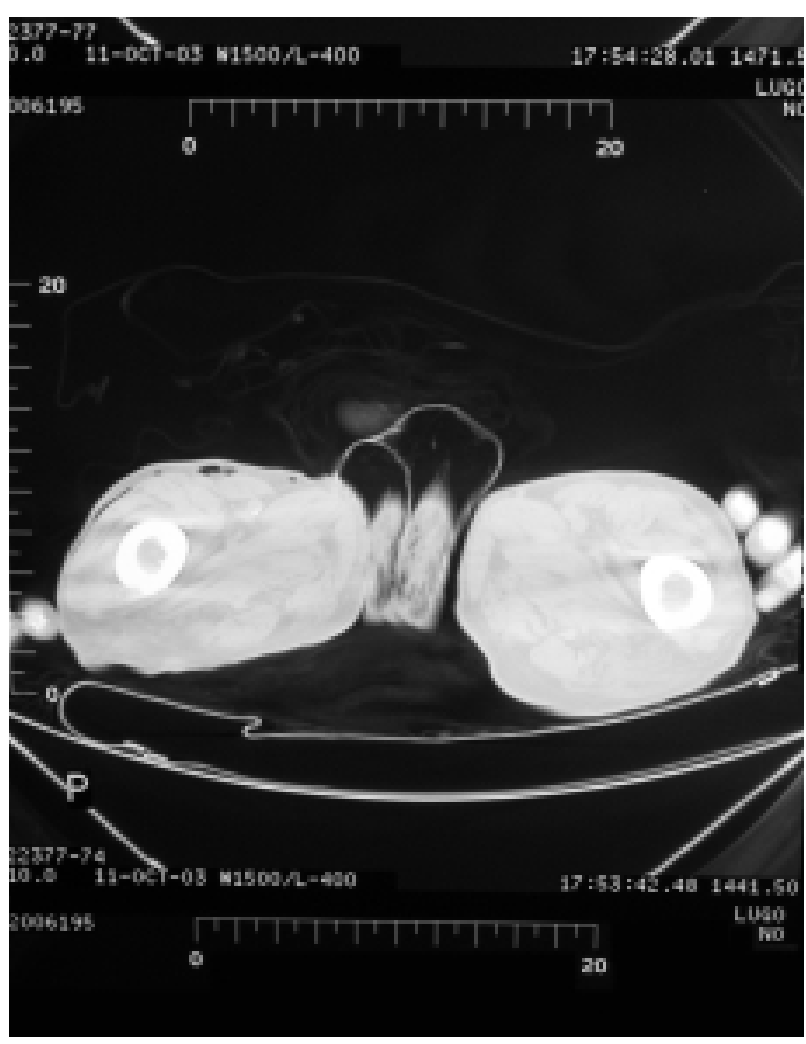

FIGURA 1. Corte por TAC de neumoescroto una vez realizado el drenaje manual de la mayor parte del contenido aéreo.

llegando distalmente hasta ambos muslos. Una vez comprobado que el pulmón derecho había reexpandido se retiró el tubo de drenaje. A través del orificio de colocación del tubo de drenaje se produjo salida del aire acumulado en el tejido celular subcutáneo adyacente, con un silbido audible. Se efectuaron maniobras de arrastre, por presión manual sobre la piel, del aire acumulado en otras zonas más distales (pectoral contralateral, base del cuello, pared abdominal) hacia la zona del orificio del tubo torácico. Finalmente. y ante el volumen que había adquirido la bolsa escrotal, se realizó una pequeña presión sobre ésta, desplazándose el aire retenido a través del tejido celular subcutáneo suprapúbico inicialmente y posteriormente a través de la pared abdominal derecha, región de hipocondrio derecho, pectoral derecho y salida por orificio de tubo de drenaje. Una vez realizada esta maniobra se selló con vaselina estéril y apósito el orificio del tubo y se adoptó actitud expectante. El paciente evolucionó bien con lenta resolución de su enfisema subcutáneo hasta la resolución total. 


\section{DISCUSIÓN}

Se define como neumoescroto la distensión de la bolsa escrotal producida por el acúmulo de aire $\mathrm{u}$ otros gases en ésta. $\mathrm{El}$ aire en la bolsa escrotal puede ser un signo inicial de enfermedades amenazantes para la vida (p.e. gangrena de Fournier) o puede representar tan solo un hallazgo casual asociado con enfermedades más benignas ${ }^{1}$.

Se han propuesto varios mecanismos patogénicos por los cuales el aire puede llegar desde una fuente lejana al escroto. En el trabajo de Millmond et al. ${ }^{2}$ se describe como la diseminación subcutánea del aire es el mecanismo patogénico más probable, partiendo éste desde la fuente de origen y diseminándose a través del tejido celular subcutáneo hasta alcanzar el escroto. Otra vía a través de la cual el aire llegaría al escroto sería la retroperitoneal, a través del canal inguinal, sobre la superficie de los cordones espermáticos. Menos probable sería la diseminación intraperitoneal de aire a la túnica vaginalis.

La mayor parte de los casos de neumoescroto descritos en la literatura médica tienen como origen del aire una fuente lejana al escroto. El enfisema escrotal está muchas veces asociado con la realización de procedimientos diagnósticos y/o terapéuticos. Los pulmones y los órganos digestivos con contenido aéreo, son los orígenes más frecuentes. La colonoscopia es una de las técnicas a las que se ha asociado el neumoescroto con mayor frecuencia ${ }^{3,4}$. Una pequeña laceración en la mucosa intestinal permite el paso del aire a presión, que llega al retroperitoneo y de ahí al mediastino y al tejido celular subcutáneo, para expandirse por debajo de la piel hasta el escroto. Posiblemente la vía retroperitoneal descrita previamente intervenga de alguna manera. Otros procedimientos en el área del aparato digestivo que se han visto complicados con neumoescroto son la biopsia hepática, la ERCP, la esfinterotomía endoscópica, la esofagoscopia (en relación con una perforación esofágica iatrogénica) y la resección endoscópica de pólipos ${ }^{5-9}$.

Los pulmones y la cavidad pleural son otros orígenes habituales del neumoescroto. Se ha descrito esta complicación en relación con resecciones pulmonares, después de la realización de maniobras de reanimación cardiopulmonar y como consecuencia de una intubación endotraqueal $^{10-12}$. Gerdin describió el caso de un neumoescroto en el cual no se pudo encontrar la fuente de origen calificándose de espontáneo ${ }^{13}$.

En nuestro caso pensamos que se produjo una diseminación subcutánea del aire que procedía de la cavidad pleural. Nuestro paciente comenzó con datos de enfisema subcutáneo tras la colocación de un drenaje torácico para resolver un neumotórax, lo que nos hace suponer que hubo pérdida de aire entre el tubo y el tejido celular subcutáneo circundante. Se podría especular sobre la posibilidad de que el enfisema subcutáneo fuera secundario a la ruptura de bullas pulmonares, presentes en éste paciente, y que el aire siguiera la vía descrita ya hace años por Macklin ${ }^{14}$; el aire pasaría desde los alvéolos al intersticio pulmonar y luego a través de las vainas vasculares hasta confluir en el mediastino, cavidad pleural, paso a través del tejido celular subcutáneo del cuello y posteriormente a través del TCS torácico, abdominal y alcanzar el escroto. Aunque esta segunda vía nos parece más rebuscada nos explicaría la imagen radiológica de probable neumomediastino que aparece al ingreso del paciente (Fig. 2). Sin embargo la ausencia total de enfisema subcutáneo en la radiografía previa a la colocación del tubo nos hacen decantarnos definitivamente por la fuga de aire a través del tubo como mecanismo patogénico.

Nos parece interesante comunicar este caso, creemos que no descrito previamente en la literatura

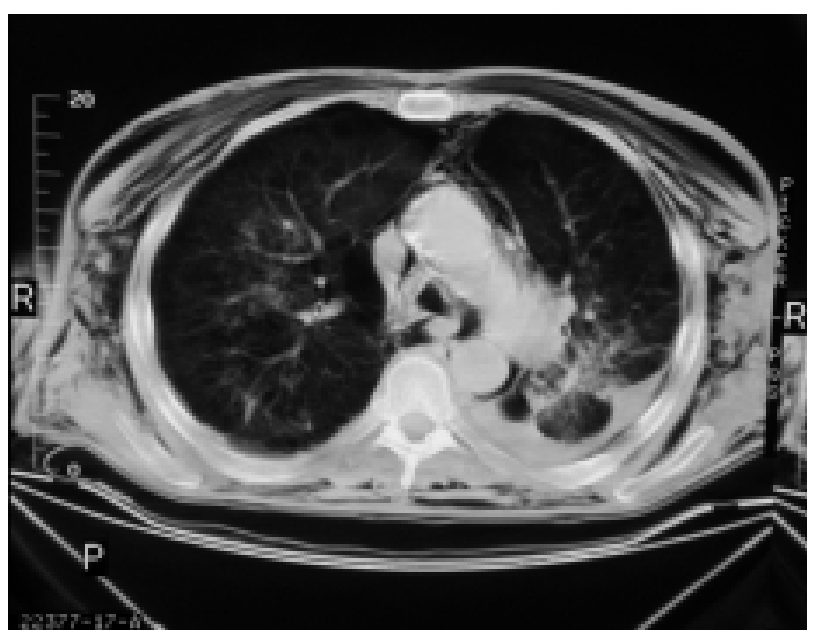

FIGURA 2. Corte por TAC en el que se puede ver el enfisema subcutáneo masivo. 
médica indexada en lengua española (búsqueda en Medline 1966-2003), puesto que se trata de una entidad que, siendo de fácil diagnostico y de manejo conservador, puede confundirse con etiologías graves y que precisan de cirugía agresiva para su tratamiento.

\section{REFERENCIAS}

1. Watson HS, Klugo RC, Coffield KS. Pneumoscrotum: report of two cases and review of mechanisms of its development. Urology 1992;40(6):517-521.

2. Millmond SH, Goldman SM. Pneumoscrotum after spontaneous pneumothorax with air leak. J Urol 1991;145(6): 1271-1272.

3. Carlsen CU, Andreassen KH. Benign pneumoperitoneum and scrotal emphysema after colonoscopy. Ugeskr Laeger 1992;154(25): 1785-1786.

4. Eisenman A, Veissler A. Subcutaneous emphysema as a complication of colonoscopy. Harefuah 1991;121(1-2):1517.

5. ENGELHARD D, ORNOY A, DECKELBAUM RJ. Pneumoscrotum complicating percutaneous liver biopsy. Gastroenterology. 1981; 80(2): 390-392.

6. LAOSEBIKAN AO, THOMSON SR, GHIMENTON F, CAMPBELL HT. Surgical emphysema of the scrotum-another complication of ERCP? S Afr Med J. 2003; 93(7): 504-5

7. SCHOENEMANN J, HABERKORN-BUTENDEICH J. Pneumopericardium and retroperitoneal and scrotal emphysema after endoscopic papillotomy. Z Gastroenterol. 2000; 38(1): 45-7
8. Mc.Courtney JS, Molloy RG, Anderson JR. Endoscopic esophageal perforation presenting as surgical emphysema of the scrotum. Gastrointest Endosc 1994;40(1):121-122.

9. Andreani T, Buffet C. Subcutaneous abdominal emphysema and pneumoscrotum after endoscopic resection of rectal polyps. Gastroenterol Clin Biol 1984;8(4):387.

10. Raudat CW, Katris F, Woodhall D. Pneumoscrotum: an unusual complication of pulmonary resection. J Am Osteopath Assoc 1996;96(6):362-363.

11. Menzies D, Noble JG, Dent CM, Cox PJ. Pneumoscrotuman unusual complication of cardiopulmonary resuscitation. Br J Urol 1991;67(4):440-441.

12. Redman JF, Pahls WL. Pneumoscrotum following tracheal intubation. J Urol 1985;133(6):1056-1057.

13. Gerdin B, Liljeholm H, Weng P. Spontaneous scrotal emphysema-a cause of scrotal swelling. Scand J Urol Nephrol 1985;19(1):77-79.

14. Macklin CC. Transport of air along sheaths of pulmonic blood vessels from alveoli to mediastinum: clinical implications. Arch Intern Med 1939;64:913.

Dr. A. Mateos Colino

(Servicio de Neumología)

Hospital Comarcal de Monforte

$\mathrm{C} /$ Corredoira, s/n

27400 Monforte de Lemos (Lugo)

(Trabajo recibido el 5 diciembre de 2003) 